\title{
Engineering roles in Building with Nature interdisciplinary design \\ Educational experiences
}

\section{Renate Klaassen', Baukje Kothuis², \& jill Slinger3,4}

\section{Delft University of Technology, 4TU Centre For Engineering Education}

2. Delft University of Technology, Faculty of Civil Engineering and Geosciences, Hydraulic Structures and Flood Risk

3. Delft University of Technology, Faculty Technology Policy Management, Policy Analysis

4. Rhodes University, Institute for Water Research 


\section{Abstract}

Building with Nature (BwN) infrastructure designs are characterised by disciplinary integration, non-linearity, diverse and fluid design requirements, and long-term time frames that balance the limitations of earth's natural systems and the socio-technical systems created by humans. Differentiating roles in the engineering design process may offer strategies for better solutions. Four complementary engineering design roles were distinguished, namely: Specialists, System Integrators, Front-end Innovators, and Contextual Engineers. The key research question addressed in this paper asks, how can the introduction of engineering roles enhance interdisciplinary processes for BwN design? Three Building with Nature design workshops with international groups of students from multiple disciplines and various education levels provided the ideal context for investigating whether engineering roles enhance such interdisciplinary ways of working. Results indicate that the application of engineering roles in each of the three workshops indeed supported interdisciplinary design. A number of conditions for successful implementation within an authentic learning environment could be identified. The engineering roles sustain an early, divergent way of looking at the design problem and support the search for common ground across the diverse perspectives of the team members, each bringing different disciplinary backgrounds to the design table. The chapter closes with a discussion on the value of engineering design roles and their significance for the Building with Nature approach.

\section{KEYWORDS}

Engineering roles, interdisciplinary ways of learning, Building with Nature design, authentic learning experiences 


\section{Introduction}

The future of engineering in society is changing dramatically as the 4th industrial revolution sets the pace for artificial intelligence that will be embedded in every aspect of our lives (Jescke, 2016) and we are confronted with increasingly complex societal problems associated with environmental challenges, such as climate change (Schwab, 2017; Kamp, 2016). In this emerging future, complex decision-making processes can no longer be realised in isolation. Instead, extensive collaboration with diverse stakeholders, a pro-active attitude, multidisciplinary expertise and technology-based and innovative solutions, are required. Building with Nature is an ecosystem-based approach to hydraulic engineering that seeks to design innovative multidisciplinary solutions rather than conventional hydraulic infrastructures (Slinger et. al., 2015; 2016). Building with Nature strives to use natural materials, ecological processes and interactions, in designing effective and sustainable hydraulic infrastructures for areas threatened by environmental and climate change (Waterman, 2010). It requires multifunctional engineering design competence and draws on knowledge of ecological systems, governance systems, and understanding of the physical and social environmental context within which the infrastructures are placed. Additionally, it requires the management of complex decision-making processes (see Bontje, 2017; Oudenhoven et al., 2018), posing challenges to the existing disciplinary and sectoral boundaries and the time frames of conventional coastal governance (Raymond et al., 2017).

Such a multifunctional, ecosystem-based approach is much needed as about eighty percent of the world population will be living in urban lowland areas by 2050 (De Vriend \& Van Koningsveld, 2012), areas which will be under threat of flooding due to to sea level rise and the increased occurrence of storms. Building with Nature projects require the involvement of specialists in ecology, economics, civil engineering and the social sciences. Additionally, local stakeholder involvement is crucial to the success of Building with $\mathrm{Na}-$ ture projects (Bontje et al., 2017). Therefore, Building with Nature requires a different way of interdisciplinary thinking and acting than most engineering fields, to arrive at a better design result (De Vriend et al., 2015).

This paper explores and evaluates the application of a training method to enhance interdisciplinary thinking. Three Building with Nature workshops form the contextual design setting in which international student teams and senior experts from diverse disciplinary backgrounds as well as a broad group of local stakeholders undertake authentic design challenges. Although Building with Nature designs require the integration of disciplinary content knowledge (a.o. civil engineering, ecology, governance, spatial design), the training is targeted at skills related to collaboration within design teams - by 
means of introducing so-called 'engineering roles' (see below). The key research question addressed in this paper therefore reads:

How can the introduction of engineering roles enhance interdisciplinary processes for BwN design?

The concept of engineering roles was first created by the Free Spirits Think Tank at Delft University of Technology in 2015 in response to the question "What do future engineers need to know?" (Kamp \& Klaassen, 2016). Four complementary roles were distinguished, namely: Specialists, System Integrators, Front-end Innovators, and Contextual Engineers. The Think Tank members considered that the increasing complexity of societal and environmental problems meant that monodisciplinary approaches would be inadequate and that simply collecting multiple disciplinary experts together in a design team would also be insufficient. Instead, a multidisciplinary team of experts skilled in adopting different engineering roles appropriate to the design context, while still honouring their disciplinary knowledge, was required. Team members need first and foremost to use their disciplinary knowledge to synthesize and integrate across different knowledge bases, but also need to be able to shift their personal (engineering) role within the design team so as to enable innovative solutions and new ways of working together (Kamp \& Klaassen, 2016).

The three one-day, place-based Building with Nature design workshops served as thematic hubs in which to test the relevance of the engineering design roles, designed by the 4TU Centre for Engineering Education, in a practical interdisciplinary educational context. The workshops were conducted under the auspices of the NSF-PIRE research program (Partnerships for International Education and Education) 'Coastal Flood Risk Reduction'. This is a collaborative partnership between Texas A\&M University in Galveston, Rice University in Houston and Delft University of Technology in the Netherlands, involving senior academics as well as $\mathrm{PhD}$, Masters and Bachelor students. An annual, two-week long exchange programme in The Netherlands forms part of the programme. The interdisciplinary, Building with Nature workshops focussed on Texel in 2016, Petten in 2017, and Kinderdijk in 2018. The first workshop in 2016 also served as a pilot intervention for the NWO CoCoChannel research project, focussed on the southwestern corner of Texel. In each of these Building with Nature workshops, the effects of the engineering design roles on the educational experience of the participants was evaluated.

After first theoretically grounding the character of the Building with Nature design process and solution space, the necessity for engineering roles within interdisciplinary design is examined (Section 2). This serves to establish Building with Nature design settings as suitable environments for learn- 
ing interdisciplinary skills. Next, the configuration of the Building with $\mathrm{Na}^{-}$ ture design sessions is described in terms of the participant selection (Section 3.1), the three design assignments (Section 3.2), their nesting within a game structuring approach in the workshops (Section 3.3), and how the evaluation of the effects of the engineering roles on the Building with Nature design processes will be undertaken (Section 3.4). In Section 4, the 2016 pilot workshop is presented in which the Building with Nature design approach is tested and the effects of the engineering roles are explored. Finally, the ways in which the engineering design roles influenced the workshop outcomes - the Building with Nature designs - and the learning of participants in 2017 and 2018 are presented and analysed in Section 5 . The chapter closes with a concluding discussion on the value of engineering design roles and their significance for the Building with Nature approach in Section 6.

\section{Theoretical grounding}

\subsection{The Building with Nature design process and solution space}

Building with Nature (BwN) is an emerging field, which requires integration across social, environmental and engineering disciplines (Slinger et al., 2016). Solutions need to be multifunctional and integrated (Kothuis, 2017). Inter- and transdisciplinary approaches offer integration processes whereby design teams can arrive at solutions that fall within a feasible boundary space. This boundary space can be envisaged similarly to the doughnut economic model (Raworth, 2017), as squeezed between societal needs and the earth system boundaries that need to be taken into account in any BwN design. The BwN solution space therefore represents a complex multidimensional space balancing the limitations of earth systems (outer blue shapes) and the socio-technical systems created by humans (inner green shapes).

The solutions space is typically multifaceted, a dynamic space changing per location and yielding different and separate insights at the case issue level, compared with the self-organising complex patterns at the overall system level (Newing, 2009). Therefore, Building with Nature solutions are characterised by disciplinary integration, non-linearity, fluid design requirements, and long-term time frames. This requires an interdisciplinary approach, merging multiple stakeholder insights. According to Fortuin (2015), educational activities which may stimulate an integrative interdisciplinary approach (particularly in the environmental sciences) should involve a real-life complex environmental problem, close collaboration in a team, changing perspectives, transcendence of disciplinary knowledge to experience complex reality, interaction with external stakeholders to encounter the norms and values held in society, and a reflection on the design/research process in the light of 
societal norms and values. A Building with Nature design process intrinsically satisfies these conditions as integration across the ecological and engineering knowledge fields is necessary, at a minimum. Additionally, the situation of the design in a particular place means that the values of local actors and the fit with the social, cultural heritage have to be taken into account. An engineering roles approach, which we will introduce below, proved to support students in adopting different perspectives as they design integrated solutions within the multifaceted, environmentally and socially dynamic Building with Nature solution space.

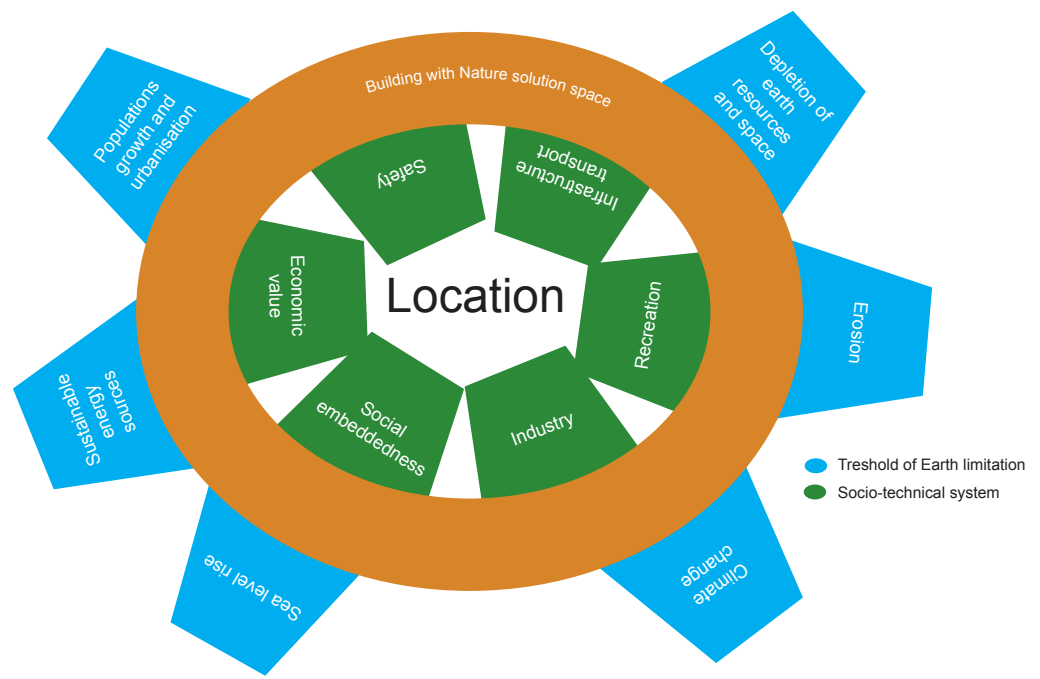

Figure 1. The Building with Nature solution space (in orange), squeezed between societal (socio-technical) needs (in green) and earth system boundaries (in blue) (adapted from Raworth, 2017). The depicted earth system boundaries and the activities such as recreation are not exhaustive or fixed, additional green and blue shapes can be added as required by the specific location.

\subsection{Engineering roles and interdisciplinary design}

The engineering roles of Specialist, System Integrator, Front-end Innovator and Contextual Engineer are defined as complementary roles applicable across diverse engineering fields from environmental engineering to aeronautical engineering, each addressing a different heuristic question, and guiding the investigation of the problem to come to a solution (Kamp \& Klaassen, 2016). While the Specialist focuses on phenomena, System Integrators emphasize the integration of different components within the overall system, Front-end Innovators address the user experience and try to bridge the gap between technology and society by designing consumer-oriented products, and the Contextual Engineer addresses the conditions under which the technology can ethically, legally and culturally be used by creating rules, regulations, or cultures of acceptance in society (Box 1). 
The following types of engineers tend to play different roles in projects and work environments, as they start with different heuristic questions (A complete description is digitally available from http://issuu.com/danielleceulemans2/docs/future_proof_profiles_digital):

- Specialist: How can we advance and optimize technology for innovations and better performance using scientific knowledge?

- System Integrator: How can we bring together disciplines, products or subsystems into a functioning whole that meets the needs of the customer/environment?

- Front-end Innovator: How can we advance and apply knowledge and use technology to develop new products for the benefit of people (end users)?

- Contextual Engineer: How can we exploit diversity-in-thought to advance and apply knowledge and use technology in different realms to develop products and processes for the benefit of people in different cultures and contexts?

Each role cannot realise a technological solution without the others and is needed to realise integrated solutions for complex problems (Kamp \& Klaassen, 2016).

Box 1. Description of the engineering roles

The engineering roles are intentionally not specified in terms that are characteristic of a particular environmental engineering discipline and thus are more abstract. They are part and parcel of the process of negotiating meaning (Beers, 2005) and this makes them potentially applicable across a broad spectrum of design problems. Ideally, the roles avoid a situation where different perspectives are merely aligned, but instead help in achieving integration rather than just aligning across diverse problem and solution perspectives. More importantly, each of these roles is essential in realizing an integrated design solution. As such, they are conceived as stimulating the integration of different disciplines and concomitant interdisciplinary ways of working.

Interdisciplinarity can be understood as combining two or more disciplines at the level of theory, methods, or solution space, to form a transcendent and innovative understanding or solution, that in turn can possibly transform the mono-discipline(s) (Repko, 2007; Menken \& Keestra, 2016; Fortuin, 2015). Two interdisciplinary ways of working can be distinguished, 
namely: within a team of experts with different disciplinary backgrounds, or an individual using the theory, methods and solutions from disciplines other than their area of expertise in seeking an answer to their research or design questions. Here, we are primarily interested in interdisciplinarity in teams. Interdisciplinarity in a team means that each participant's disciplinary constructs, concepts, and procedures are brought into question, are criticized and debated, as similar terminology often holds different meanings within different disciplines. The factual knowledge of participants and their reflective and problem-solving skills across tasks and solutions, constitute elements of the interdisciplinary learning process (Stentoft, 2017). This prompts them to challenge their prior beliefs and requires participants to remain open to review and even redefine their understanding and ideas (Boix Mansilla, 2010).

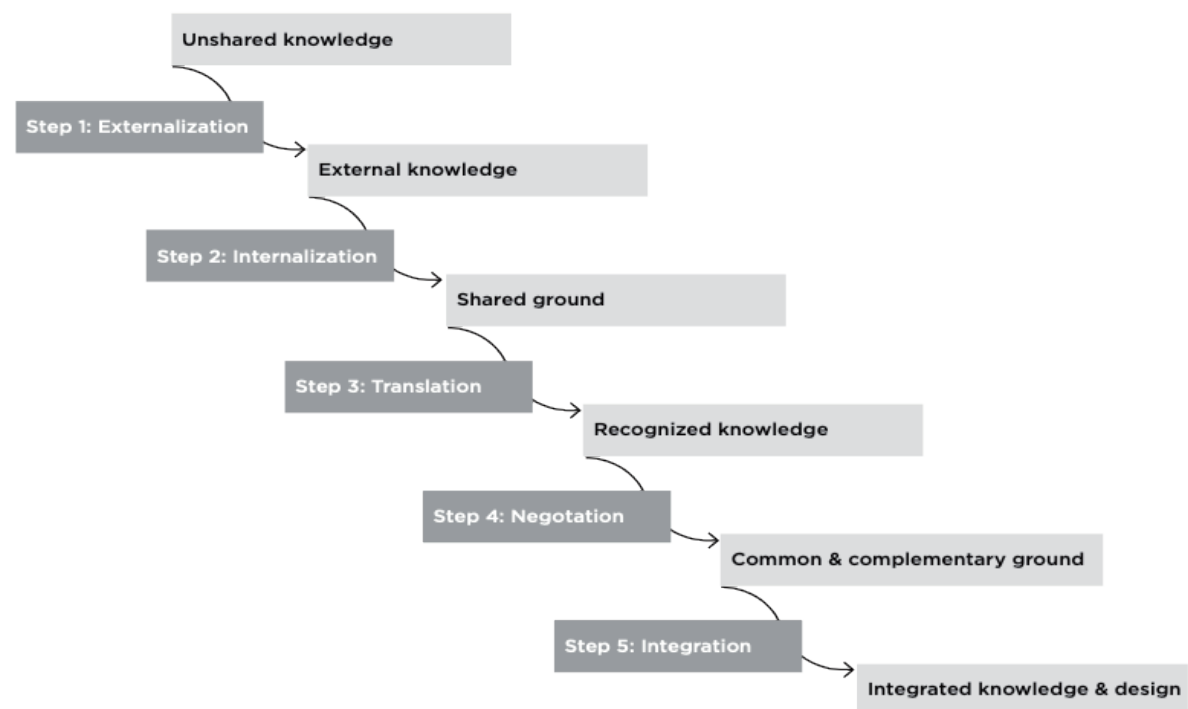

Figure 2. From unshared to integrated knowledge by B.L.M. Kothuis (2017, p. 218) adapted from P. Beers, (2005, p. 12)

Redefinition involves clarifying or modifying the concepts and assumptions used by relevant disciplines in order to reach a common meaning (Repko, 2007). According to Beers (2005), engaging people's thinking in interdisciplinary teams is a demonstrated precondition for richer solutions to complex problems. Creating common ground, in which meaning is aligned through negotiation with all the team members, is thus necessary for the construction of shared knowledge (Beers, 2005; Van den Bossche et al., 2006). Whereas Beers (2005) distinguishes four steps as necessary to move from unshared to constructed knowledge in multidisciplinary teams, Kothuis (2017) adds an extra step to arrive at integrated knowledge and design. She affirms that an 
additional step in which the shared knowledge is translated into recognizable knowledge for the disciplines involved in the design process, is essential in moving to truly integrated knowledge. Moreover, Kothuis (2017) has shown that this conceptual model of knowledge construction through negotiation is a valuable tool, particularly in Building with Nature research teams.

Team members will hold different assumptions and values on how to conduct an interdisciplinary effort. Being open to ways of doing outside of a participant's own discipline is challenging. Accordingly, differences in value sets and assumptions regarding outcomes need to be identified and negotiated in meaning making discussions (Jay et al., 2017). The idea is that engineering roles may assist in engaging in such "negotiation of meaning" (Beers, 2005).

Hooimeijer et al. (2016) demonstrated that the engineering roles take on different levels of relative importance depending on the context and phase of a design. The engineering design roles are minimally interdependent to facilitate the flexible realisation of an integrated solution. Different roles are needed in different phases of the design process. For instance, each Specialist has monodisciplinary knowledge that is then provided to a System Integrator who builds larger objects, systems or services, or to a Front-end Innovator who designs products, systems or services needed by industry or the public. The Contextual Engineer facilitates the technological innovations and may have the role of, or support, a client, a government authority, a legal or cultural change agent.

The claim is that engineering roles stimulate an interdisciplinary approach to the realisation of common ground within a design team, including discussions about norms and values across disciplines and an appreciation of diverse stakeholder perspectives. They help in shifting perspectives, finding and recognizing common ground, and in the development of more innovative and integrated solutions, so that they fall within the Building with Nature solution space doughnut.

\section{Designing the Building with Nature design workshops}

\subsection{Participant Selection}

As an innovative design concept, the Building with Nature workshops were intended to extend the participants beyond their comfort zone. Each workshop was attended by between 20 and 30 carefully selected participants with different disciplinary backgrounds, nationalities and levels of education. In 2016, there were 10 students from educational organisations in the Neth- 
erlands (2 Phd's, 8 MSc's), and 9 students from educational organisations in the United States of America (USA), (6 Phd's, 2 MSc's, 1 BSc), In 2017 there were 10 from the Netherlands (2 Phd's, 7 Msc's, 1 BSc) and 16 from the USA (5 Phd's, 3 MSc's, 7 BSc's). In 2018, there were 12 from the Netherlands (3 PhD's, 9 MSc's) and 16 from the USA (4 Phd's, 4 MSc's, 8 BSc's). The institutions involved were Delft University of Technology, the University of Twente, Vrije Universiteit (VU) Amsterdam, IHE-Delft, Texas A\&M, Rice University and Jackson State University. Each of the American student participants went through a stringent selection process in Texas, involving a personal motivation letter and interview. The Dutch students were selected based on their disciplinary backgrounds to ensure a wide distribution across disciplinary fields. The senior researchers, experts and local stakeholders were selected based on their interests, local knowledge and their ability to communicate about their disciplinary expertise in an understandable manner. Accordingly, the disciplines of all the participants differed substantially, ranging from civil engineering to spatial planning, economics, ecology, hydrology, architecture, computational hydraulics, communication, oceanography and policy analysis. The backgrounds of the local stakeholders varied, but a representative of the local water authority and a Building with Nature expert was present in each case.

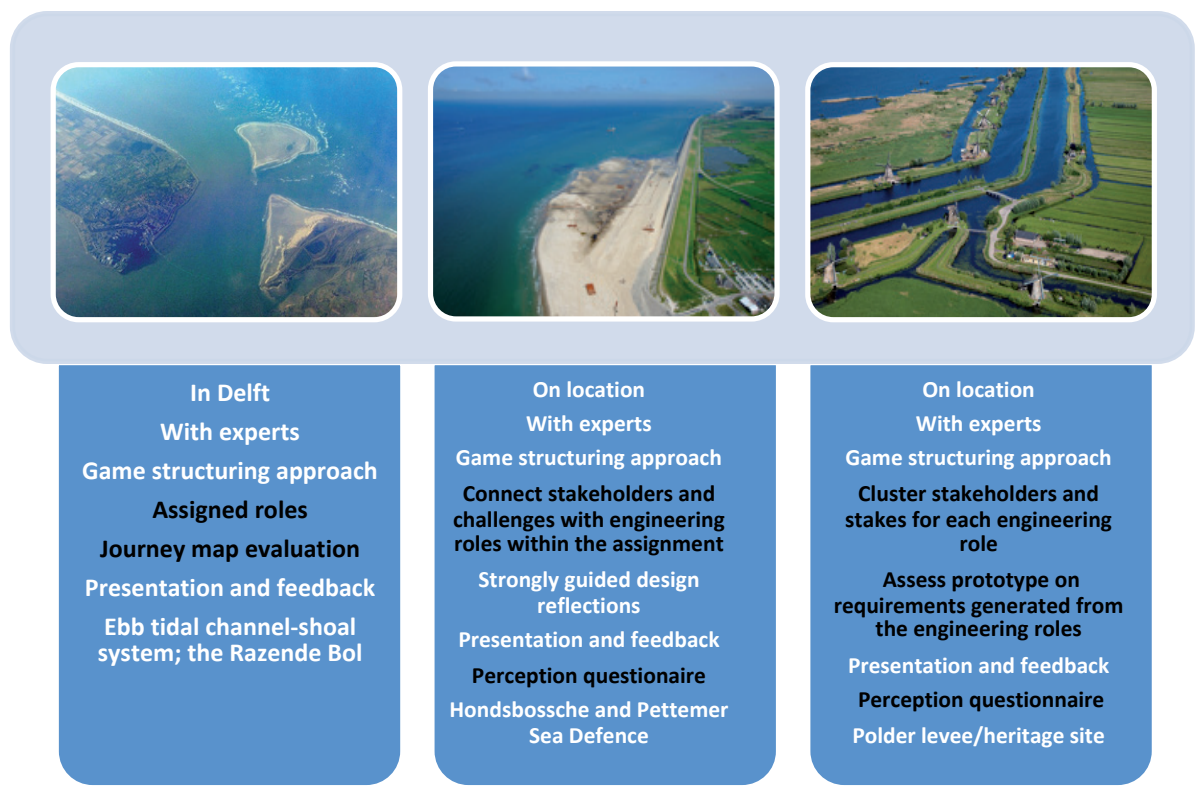

Figure 3. Case study contexts for the Building with Nature design workshops in 2016, 2017, and 2018, indicating the form that the engineering role intervention took in each case (in black). 


\subsection{Design Assignments}

The design assignments given to the participants in the workshops represent real-world, societal challenges in which innovative solutions are required for long-term flood defence. Each of the assignments required the integration of knowledge on the dynamics of the bio-geophysical system into the engineering design process. Further, each assignment required the integration of the local knowledge of stakeholders regarding values, norms and social and ecological system functioning to arrive at a feasible Building with Nature solution to the local long-term flood defence problem. The design assignments for each of the workshops are listed in Box 2.

Each design team was required to (i) name and depict their Building with Nature design with diagrams and drawings, (ii) describe the dynamic characteristics of the design, (iii) describe their design process, and (iv) provide a 5 minute poster pitch. They were supplied with a bucket of material, including handouts with background information and maps of the case study site as well as writing, drawing and crafting material. The material was supplied to encourage them to be creative in fulfilling the design requirement instructions and preparing their Building with Nature design pitch for the other teams, local stakeholders and experts.

2016 Texel: Design alternative coastal management strategies (or improve the current strategy) using the natural channel-shoal dynamics to ensure safety from flooding and serve other functions

2017 Petten: The Hondsbossche and Pettemer Sea Defence no longer met the required safety standards. Design alternative coastal protection strategies (or improve the current strategy) so as to comply with required safety standards both now and in 2050, taking compatibility with the bio-physical, social and institutional environment into account in your integrated design.

2018 Kinderdijk: The Alblasserdam-Kinderdijk dike requires strengthening to continue to meet flood safety standards. Produce integrated designs for the area that achieve flood safety for the Alblasserwaard polder, as well as improving the accessibility of Kinderdijk, and creating additional ecological value through the application of Building with Nature principles. 
The assignments focused on collaborative design activities to engender learning. Each assignment served as a catalyst for interdisciplinary assessments of physical flood risk and modelling, characterising the socio-economic setting, analysing land-use change and the built environment, and coming up with innovative designs and mitigation measures to address residual impacts. In each case, attention was paid to the effectiveness of hard structures as opposed to soft flood defence infrastructures in combating the adverse effects of flood events.

The case study locations of the "Razende Bol" near Texel (2016), the Hondsbossche and Pettemer Sea Defence at Petten (2017) and Kinderdijk near Ablasserdam (2018) are depicted in Figure 3.

\subsection{A game structuring approach}

The game structuring method was first applied successfully in South Africa (Slinger et al., 2014) before being implemented in Houston in Texas (Kothuis et al., 2014), on Texel in the Netherlands (d'Hont \& Slinger, 2018), and in Tema in Ghana (Kothuis \& Slinger, 2018). The game structuring method represents an extension to problem structuring approaches, and is focused on incorporating diverse stakeholder values into a common understanding of a complex real-life problem situation (Cunningham et al., 2014). The method comprises a series of six steps, namely:

\section{Get acquainted}

2. Identify stakeholders and main interest groups

3. Determine relevant systems and their values (how they are used and appreciated)

4. Develop possible outcomes

5. Vote on the outcomes

6. Explore the space for commitment to action.

Step 4 is the integrated design step in which the design teams develop different potential solutions and outcomes. In each of the three Building with Nature design workshops this step was nested within Steps 2 to 5, which are deemed necessary for obtaining sufficient contextual information to be able to design. Step 6 was omitted as this is most relevant for workshops in which local residents and authorities commit to engaging in complex decision making processes for their area. Experts provided information via presentations in Step 3, and Step 2 was sometimes preceded by a presentation by a local stakeholder or water authority representative to provide information on local interests, concerns, and regulations. In a game structuring workshop, participants are encouraged to consider negative, as well as positive, future outcomes (i.e. utopian and dystopian design outcomes) so as to extend the solu- 
tion space by considering a broad range of options. Dystopian futures often provide sharp insights into the values held by stakeholders.

In 2017 and 2018, following the evaluation of the pilot design workshop (see section 3.4), Steps 2 and 3 were explicitly integrated with the engineering design roles and a final evaluation/reflection step was added.

\subsection{Evaluation of the effects of the engineering roles}

The introduction of the engineering roles concept into the three Building with Nature design workshops may be viewed as an intervention in a complex socio-technical and environmental system (McKenney \& Reeves, 2018) aimed at establishing whether and to what extent engineering roles enhance interdisciplinary ways of working in Building with Nature design processes. Because little is known of the utility and effectiveness of the engineering roles in design education, the first workshop represents a pilot intervention, and the following two workshops represent iterations to improve upon the experiences of the previous workshop(s).

The 1st Building with Nature Living Lab Workshop in 2016 was conducted in Delft, but was attended by experts and local stakeholders familiar with southwest Texel. A role questionnaire was administered to determine the preferred role of each participant, and was then used to compose teams with mixed roles ( 4 roles in one team), nationalities, disciplines and education levels. The preferred roles could mostly be enacted within the design teams. Where this was not possible, participants were assigned a role different from their preferred role. Significant time was allocated to explaining the engineering roles to the participants. At the end of the workshop, they evaluated the engineering roles by filling in a journey map (figure 4). This evaluation method is qualitative, and aims to gain as much insight as possible into the perception and experiences of the participants with the engineering roles. Key aspects of the design process (e.g. design process, consultations) are visualized on the journey map and participants map their experiences as positive, neutral, or negative with respect to these key aspects (open circles), and sub-aspects (closed circles) (Table 1 and Figure 4). Subsequently, the qualitative data from the journey map were clustered and used in redesigning the intervention for the next workshop. Other evaluations included the observations of the workshop facilitators.

\begin{tabular}{|c|c|c|c|}
\hline Design process & Consultations & Roles & Needs for coaching \\
\hline Problem definition & Experts & Value for education & In future education \\
\hline Design criteria & Stakeholders & Crossdisciplinary & \\
\hline Exploration of solutions & Others & perspectives & \\
\hline
\end{tabular}

Table 1. Aspects and sub-aspects of the design process as mentioned on the Reflection journey map in Figure 4. 


\section{Reflection journey map on Design Roles}

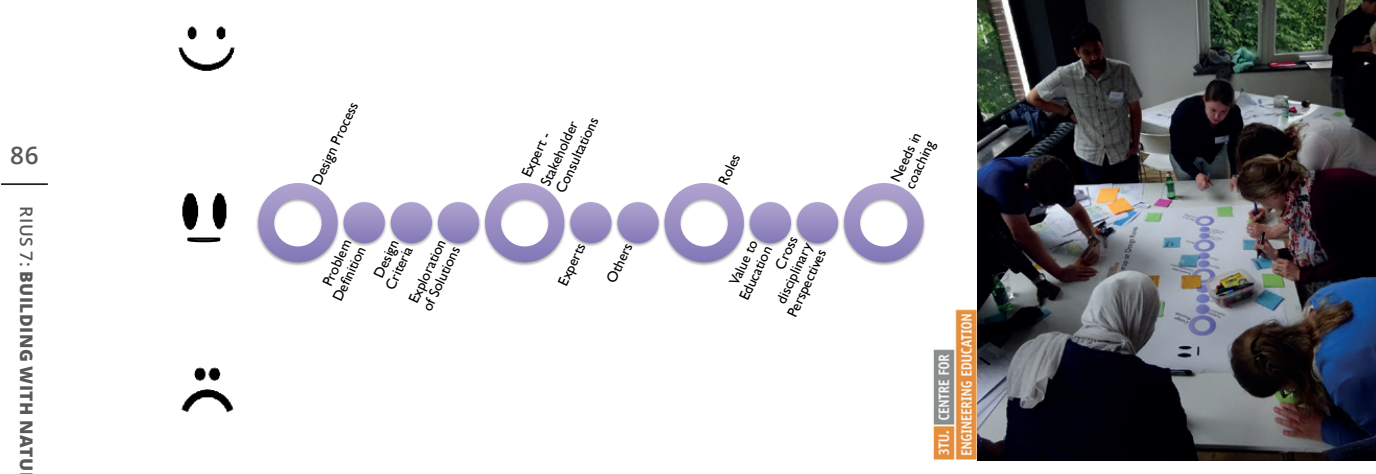

Figure 4. Evaluation of the engineering roles used in the 1st Building with Nature Design workshop.

In 2017, the design problem concerned the strengthening of the Hondsbossche and Pettemer Sea Defence, near Petten in North-Holland. The workshop was held on location. Drawing on the experiences of the previous year, the engineering roles were no longer assigned specifically to individuals, but formed an integral part of the design assignment. Prior to the workshop, the participants completed the "Engineering Role Questionnaire" to discover their preferred engineering roles. Each team member was then assigned responsibility for ensuring that a particular engineering role perspective (possibly their preferred role, but not necessarily) was adopted in the design process, yet every team member could give input on each role. The engineering roles were integrated into Steps 2 and 3 of the game structuring method, and the evaluation was administered via a questionnaire in the bus on the return journey. The questionnaire comprised sixteen ( 5 point Likert scale) questions regarding participants' perceptions of the elements in the workshop process relating to the engineering roles; the explanation of the roles, the use of the roles in the design process, the impact on negotiation of meaning and the relevance of the engineering roles. The questionnaire had a 100\% response rate (25 out of 25). The reliability (internal consistency of the questionnaire) expressed in the Cronbach alpha (measuring from .oo unreliable to 1.0 reliable) is .93. Results are presented by means of descriptive frequencies, as the participant numbers do not allow statistical analysis beyond descriptive results.

The $3^{\text {rd }}$ workshop was held on location at Kinderdijk with the same engineering role allocation process as in 2017. The design worksheet (figure 5) was simplified so that completing the engineering roles component of the workshop required less time. Consequently, the roles were only considered in Step 4 of the game structuring process where the stakeholders and challenges were clustered from the perspectives of the four engineering roles. The engineering roles were also used in the final phase to reflect back on the extent to which the design criteria were considered and met in the final designs, and to 
make sure the different stakes originating from the role's perspectives were covered. Additionally a substantive content-based evaluation was undertaken at the end of the $3^{\text {rd }}$ workshop, while the evaluation was administered via a questionnaire in the bus on the return journey. The questionnaire contained thirty (5 point Likert scale) questions about recognition, usefulness, ease of use and so on, and had a response rate of 27 out of 27 . This questionnaire contained many of the same questions as the 2017 version and a number of additional questions. The internal consistency of the questionnaire, its reliability, measured by Cronbach's alpha is .91. Results are again presented as descriptive frequencies owing to the low number of participants.

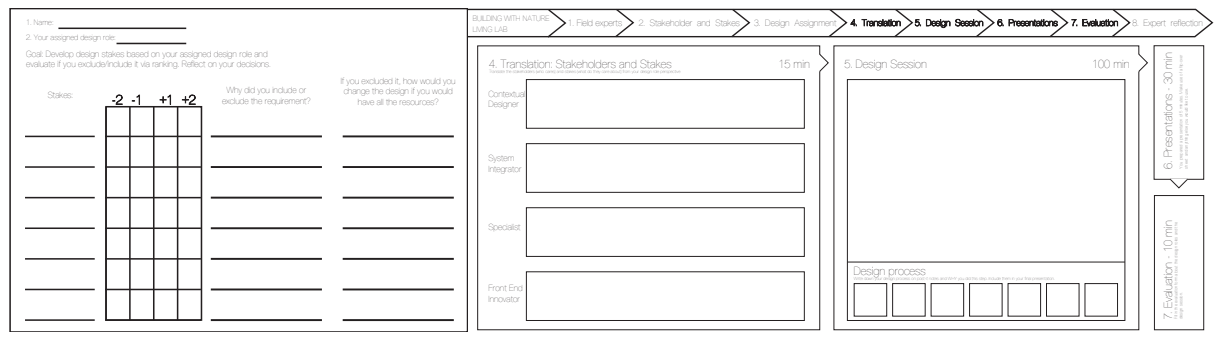

Figure 5. Design worksheet 3rd workshop at Kinderdijk.

\section{Piloting the engineering roles within a Building with}

\section{Nature design process}

In the pilot workshop in 2016, the potential Building with Nature solutions generated by the different design teams were diverse, and were characterized by substantial attention for dynamic natural processes and societal interests such as education (figure 6). The input from stakeholders via presentations and their availability for consultation during the day meant that the final designs included new and relevant Building with Nature knowledge.

The positive, neutral and negative issues identified by the participants in each of the keyword categories on the journey map used in evaluating the engineering roles in the first workshop in 2016 are reported in Table 2. Selected quotes provide an impression of the findings in relation to the engineering design roles and the responses they elicited.

Participants indicated that the engineering roles forced them to think about different issues in the design process and to explore different perspectives on the problem. In general, they facilitated the definition of boundaries for the solution space. Finally, they gave structure to the design process, helped them to think outside of the box yet to keep a clear focus and not get lost in engineering detail. 

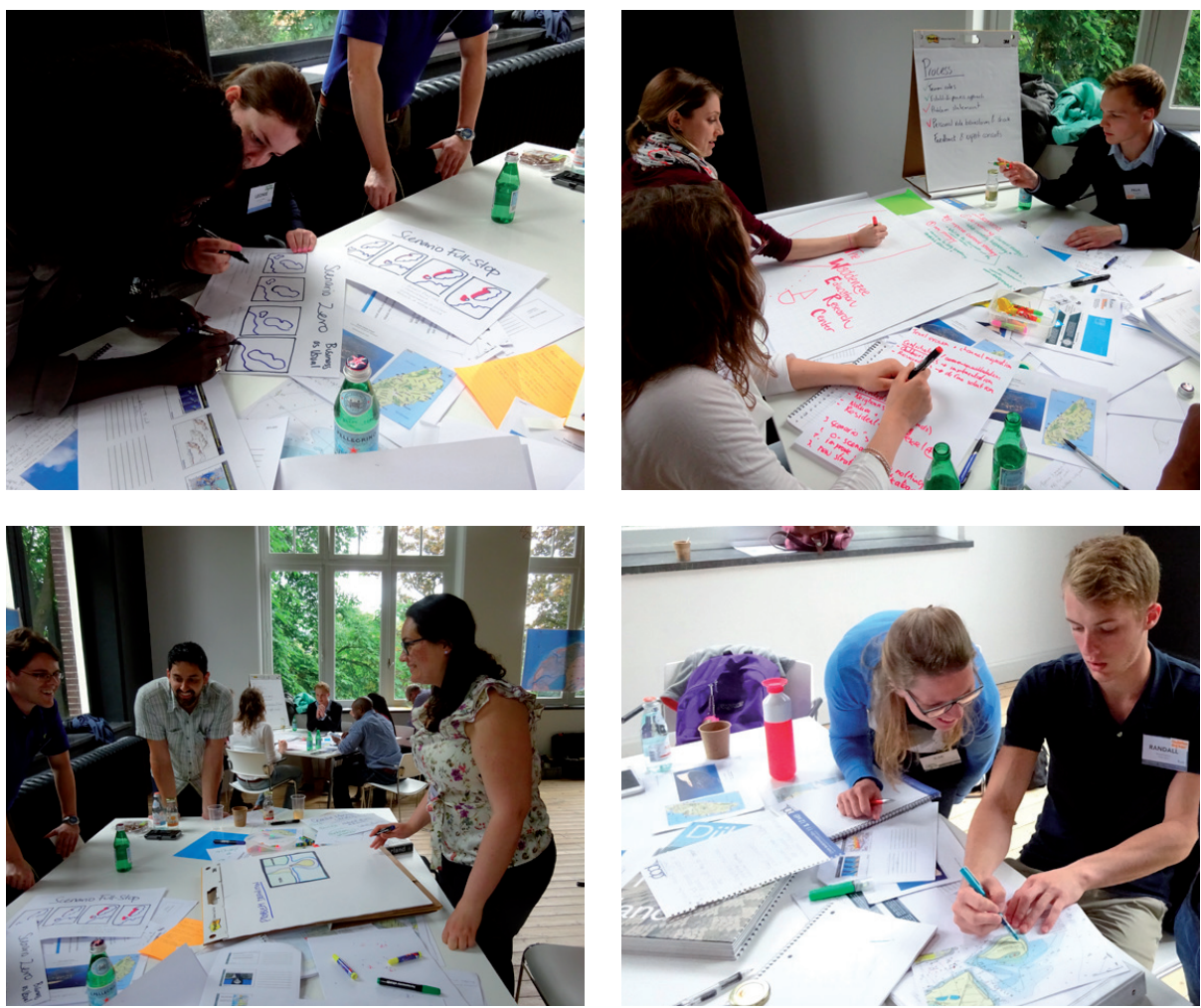

Figure 6. Teams involved in designing integrated Building with Nature solutions for the Razende Bol pilot case study near Texel.

The stakeholder consultations were divided into the identification of stakeholders for the design versus the consultation of experts who were present at the workshop. Participants indicated that they valued the experts' input: "Experts were awesome!!". Consultations helped in deepening an understanding of the dynamics of the problem situation regarding the "Razende Bol" at Texel.

The feedback on the adoption of the engineering roles was diverse. Some participants claimed that their design team used all the engineering roles. Others stated that they were better helped by the disciplinary background information provided by experts in presentations.

Some queried whether the roles actually added to the design assignment at all. Still others remarked that the roles helped in deciding "what to talk about", and there were three people who identified completely with their engineering roles. Most of the participants who failed to enact their role indicated that they did not understand their roles, felt pressured, or had an equal score on different roles, or simply had a "good" group process without adopting the engineering roles. All in all, there was a diverse experience amongst the participants in regard to engineering role adoption. 


\begin{tabular}{|c|c|}
\hline \multicolumn{2}{|c|}{ The design process [19 post-its: 15 positive, 2 neutral, 2 negative] } \\
\hline Positive & $\begin{array}{l}\text { "This was my "natural" role, although I had a tie between specialist, system integrator and } \\
\text { contextual engineer. I found this role best fitting to my personality and working strategy." }\end{array}$ \\
\hline Neutral & $\begin{array}{l}\text { "Everyone in the group contributed to the design process. I did very well in defining the } \\
\text { problems, however the diversity in the group roles didn't match with one approach." }\end{array}$ \\
\hline Negative & $\begin{array}{l}\text { "Having a given role made me feel like I had to be in that role and the other roles I } \\
\text { couldn't participate in and felt pressured to be only in that role." }\end{array}$ \\
\hline \multicolumn{2}{|c|}{ Stakeholder consultations [10 post-its: 5 positive, 1 neutral, 4 negative] } \\
\hline Positive & "Think about pros/cons doing whole process." \\
\hline Negative & "Morning brainstorming on stakeholders/challenges took too long." (3x) \\
\hline \multicolumn{2}{|c|}{ Roles [21 post-its: 7 positive, 5 neutral, 9 negative] } \\
\hline Positive & $\begin{array}{l}\text { "Working with students from other disciplines and filing different roles made me think out } \\
\text { of (my) the box!!" }\end{array}$ \\
\hline Neutral & "Need more information on specific roles and some orientation on roles might help." \\
\hline Negative & $\begin{array}{l}\text { "I was an expert/specialist based on the survey. But, I personally do not know anything } \\
\text { about the subject. So, that did not help with the design procedure." }\end{array}$ \\
\hline \multicolumn{2}{|c|}{ Crossdisciplinary perspectives [ 8 post-its: 6 positive, 1 neutral, 1 negative] } \\
\hline Positive & $\begin{array}{l}\text { "I like being in this role b/c I had to look @ many aspects of these issues, not just one } \\
\text { specific one." }\end{array}$ \\
\hline \multicolumn{2}{|c|}{ Coaching needs [7 post-its, 3 neutral, 4 negative] } \\
\hline Neutral & $\begin{array}{l}\text { "I would need more coaching in what my role really means to profit from it, other than I } \\
\text { just do what I always do. Also I took the role of specialist a bit, not really working with the } \\
\text { roles." }\end{array}$ \\
\hline
\end{tabular}

Table 2. Responses of participants to the engineering design roles in the 2016 Texel workshop.

While the value for education was not rated highly, the relevance of the engineering roles for interdisciplinary design largely received positive feedback. Most participants emphasised the usefulness of different perspectives in identifying strengths and weaknesses in the designs. The roles helped in keeping the overall design objective as the focus instead of the expertise of individuals, and supported learning from people with other disciplinary backgrounds.

Clearly, future design assignments need to include structured guidance from a role perspective for participants to benefit optimally from the engineering roles. The provision of specific information on the engineering roles in advance and during the workshop could support enacting the roles more effectively. Based on this insight and the successful application of the game structuring approach in aiding students to develop Building with Nature designs in this pilot application, the 2017 workshop design was adapted to explicitly link the presenting experts and their preferred roles and to provide a worksheet to guide the participants in the design process from a role perspective. No changes were made to the game structuring approach. 


\section{Engineering roles in the interdisciplinary design processes}

In 2017 and 2018, the integrated Building with Nature designs produced by the participants ranged widely across the potential solution space. All designs included biophysical and social elements and adopted a long-term time frame. In the Hondsbossche Pettemer case study, participants placed more emphasis on the design requirements in relation to stakeholder values and engineering perspectives, whereas in 2018 , the participants paid more attention to the problem definition, taking the local constraints to the solution space into account. This led to slightly less diverse designs for the tidal river area of the Ablasserdam-Kinderdijk.

The distribution of engineering role preferences across the workshop participants in 2017 and 2018 are depicted in Figure 7. In 2017 the majority of participants preferred the specialist role or multiple roles, and there were few system integrators. By contrast, in 2018 nearly half the participants preferred a Contextual Engineering role, with 33\% exhibiting a System Integrator profile and $17 \%$ preferring the Specialist role. Noteworthy is that the Front-end Innovator role is completely absent in 2018. All four roles were assigned to the design teams, which meant that some participants, and teams, had to leave their comfort zone(s) and adopt a new way of thinking supported by the engineering role.

\section{Engineering Role preferences}

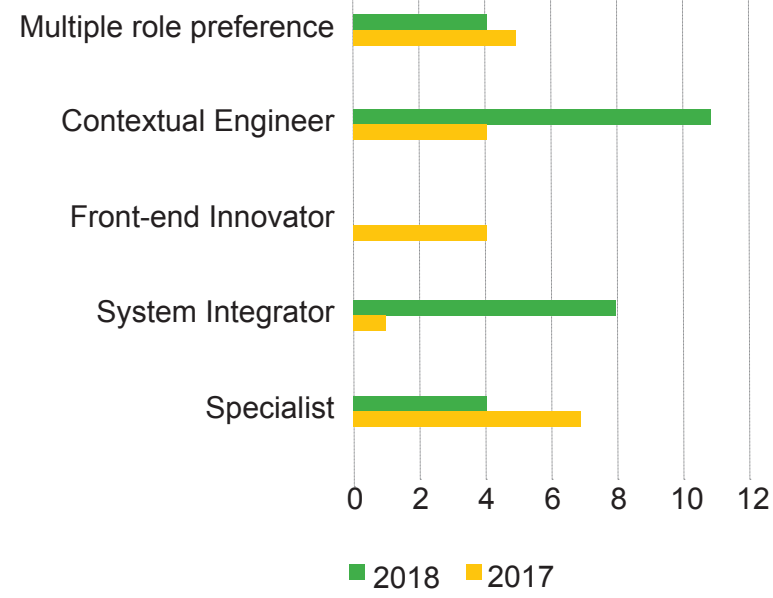

Figure 7. Distribution of engineering role preferences across the participants in 2017 and 2018.

The perceptions of participants regarding the engineering roles in the 2017 and 2018 Building with Nature workshops is reported in Table 3 and analysed thereafter. 


\begin{tabular}{|c|c|c|c|c|c|}
\hline & \multirow{2}{*}{$\begin{array}{l}\text { Questions } \\
\text { Explanation }\end{array}$} & \multicolumn{2}{|c|}{$\%$ on a scale from $1-5$ aggregated } & \multicolumn{2}{|c|}{ Mean (variance) } \\
\hline & & 2017 & 2018 & 2017 & 2018 \\
\hline 1 & The roles were clearly explained & $\begin{array}{l}46 \% \text { (strongly) agreed } \\
26 \% \text { neutral } \\
27 \% \text { (strongly) disagreed }\end{array}$ & $\begin{array}{l}33 \% \text { (strongly) agreed } \\
30 \% \text { neutral } \\
38 \% \text { (strongly) disagreed }\end{array}$ & $3.3(1.1)$ & $2.9(.97)$ \\
\hline \multirow[t]{2}{*}{2} & $\begin{array}{l}\text { I recognized the role in the } \\
\text { behaviour of the experts that } \\
\text { presented at the beginning of } \\
\text { the day }\end{array}$ & $\begin{array}{l}63 \% \text { (strongly) agreed } \\
30 \% \text { neutral } \\
8 \% \text { disagreed }\end{array}$ & $\begin{array}{l}59 \% \text { agreed } \\
30 \% \text { neutral } \\
11 \% \text { disagreed }\end{array}$ & $3.8(.91)$ & $3.4(.96)$ \\
\hline & The Design Process & & & & \\
\hline 3 & $\begin{array}{l}\text { I have made use of my personal } \\
\text { engineering role during the } \\
\text { session }\end{array}$ & $\begin{array}{l}77 \% \text { (strongly) agreed } \\
19 \% \text { neutral } \\
4 \% \text { strongly disagreed }\end{array}$ & $\begin{array}{l}33 \% \text { (strongly) agreed } \\
29 \% \text { neutral } \\
37 \% \text { (strongly) disagreed }\end{array}$ & & $3.6(.89)$ \\
\hline 4 & $\begin{array}{l}\text { I felt the roles opened up new } \\
\text { perspective in the problem defini- } \\
\text { tion phase / The roles helped } \\
\text { open up a variety of stakes }\end{array}$ & $\begin{array}{l}61 \% \text { (strongly) agreed } \\
15 \% \text { neutral } \\
23 \% \text { disagreed }\end{array}$ & $\begin{array}{l}48 \% \text { (strongly) agreed } \\
22 \% \text { neutral } \\
29 \% \text { (strongly) disagreed }\end{array}$ & $3.6(1.1)$ & $3.1(1.06)$ \\
\hline 5 & $\begin{array}{l}\text { The roles helped define the } \\
\text { design requirements }\end{array}$ & $\begin{array}{l}54 \% \text { (strongly) agreed } \\
11 \% \text { neutral } \\
29 \% \text { (strongly) disagreed }\end{array}$ & & $3.4(.79)$ & \\
\hline 6 & $\begin{array}{l}\text { The roles helped to create a } \\
\text { framework for approaching the } \\
\text { design challenge }\end{array}$ & $\begin{array}{l}65 \% \text { (strongly) agreed } \\
15 \% \text { neutral } \\
15 \% \text { disagreed }\end{array}$ & & $3.7(.97)$ & \\
\hline 7 & $\begin{array}{l}\text { The roles have contributed to the } \\
\text { structure of the design process }\end{array}$ & $\begin{array}{l}65 \% \text { (strongly) agreed } \\
26 \% \text { neutral } \\
7 \% \text { disagreed }\end{array}$ & & $3.7(.87)$ & \\
\hline 8 & $\begin{array}{l}\text { The reflection part of the } \\
\text { worksheet helped to close the } \\
\text { design loop (meet requirements } \\
\text { sufficiently) }\end{array}$ & $\begin{array}{l}45 \% \text { (strongly) agreed } \\
27 \% \text { neutral } \\
24 \% \text { (strongly) disagreed }\end{array}$ & & & \\
\hline \multirow[t]{2}{*}{9} & $\begin{array}{l}\text { Working on the worksheet added } \\
\text { quality to our final results }\end{array}$ & $\begin{array}{l}57 \% \text { (strongly) agreed } \\
27 \% \text { neutral } \\
11 \% \text { disagreed }\end{array}$ & & & \\
\hline & Negotiation of meaning & & & & \\
\hline 10 & $\begin{array}{l}\text { The roles supported a broad } \\
\text { discussion on engineering } \\
\text { solutions }\end{array}$ & $\begin{array}{l}61 \% \text { (strongly) agreed } \\
19 \% \text { neutral } \\
15 \% \text { disagreed }\end{array}$ & & & \\
\hline \multirow[t]{2}{*}{11} & $\begin{array}{l}\text { The roles helped me to create } \\
\text { common ground between the } \\
\text { different perspectives that could } \\
\text { be taken }\end{array}$ & $\begin{array}{l}45 \% \text { (strongly) agreed } \\
31 \% \text { neutral } \\
20 \% \text { (strongly) disagreed }\end{array}$ & & & \\
\hline & Relevance of working with engin & eering roles & & & \\
\hline 12 & $\begin{array}{l}\text { I can see the relevance of these } \\
\text { roles for building with nature } \\
\text { design sessions }\end{array}$ & $\begin{array}{l}81 \% \text { (strongly) agreed } \\
8 \% \text { neutral } \\
8 \% \text { disagreed }\end{array}$ & $\begin{array}{l}45 \% \text { (strongly) agreed } \\
37 \% \text { neutral } \\
18 \% \text { (strongly) disagreed }\end{array}$ & & $3.4(1.04)$ \\
\hline 13 & $\begin{array}{l}\text { The roles have added value for } \\
\text { education }\end{array}$ & $\begin{array}{l}77 \% \text { (strongly) agreed } \\
15 \% \text { neutral } \\
4 \% \text { disagreed }\end{array}$ & $\begin{array}{l}52 \% \text { (strongly) agreed } \\
33 \% \text { neutral } \\
11 \% \text { disagreed }\end{array}$ & & $3.8(1.4)$ \\
\hline 14 & $\begin{array}{l}\text { The roles have added value for } \\
\text { the (technical) work environment }\end{array}$ & $\begin{array}{l}72 \% \text { (strongly) agreed } \\
20 \% \text { neutral } \\
4 \% \text { disagreed }\end{array}$ & $\begin{array}{l}59 \% \text { (strongly) agreed } \\
11 \% \text { neutral } \\
30 \% \text { disagreed }\end{array}$ & & $3.4(1.04)$ \\
\hline 15 & $\begin{array}{l}\text { I can see the relevance of the } \\
\text { roles for my disciplinary field }\end{array}$ & $\begin{array}{l}77 \% \text { (strongly) agreed } \\
15 \% \text { neutral } \\
4 \% \text { disagreed }\end{array}$ & $\begin{array}{l}30 \% \text { (strongly) agreed } \\
37 \% \text { neutral } \\
33 \% \text { (strongly) disagreed }\end{array}$ & & $3.0(1.05)$ \\
\hline 16 & $\begin{array}{l}\text { I would recommend others } \\
\text { to experience working with } \\
\text { engineering roles/I would } \\
\text { recommend working with the } \\
\text { roles to a friend }\end{array}$ & $\begin{array}{l}63 \% \text { (strongly) agreed } \\
23 \% \text { neutral } \\
8 \% \text { disagreed }\end{array}$ & $\begin{array}{l}67 \% \text { (strongly) agreed } \\
22 \% \text { neutral } \\
11 \% \text { disagreed }\end{array}$ & & \\
\hline
\end{tabular}

Table 3. Perceptions on the engineering design roles in the 2017 \& 2018 Building with Nature workshops. 
In the 2017 workshop, a dedicated approach to working with the engineering roles was instituted. The engineering roles were positively received (Table 2) as participants considered that they supported the design process by opening up new perspectives and instituting a broader discussion of potential engineering solutions, such as solutions that include dynamic ecological processes or changes in social needs over time. Most participants adopted their engineering roles during the design process and view the engineering roles as relevant to Building with Nature design processes.

Prior to the workshop in 2018, the participants received an online leaflet and handout with engineering role descriptions. While only nine people reported reading the online leaflet prior to the workshop, the handout supported 16 people in their interpretations of the engineering roles. The workshop started later than planned in 2018 owing to traffic delays, and the explanation of the engineering roles was rushed. This is reflected in lower score assigned to the factor "The roles were clearly explained" in 2018, compared with 2017 (Table 2).

In 2017, 77\% made use of their engineering roles, whereas in 2018 half of the participants did not work with the engineering roles (Question 3, Table 2 ), although they recognised their relevance (Question 12). In 2018, 45\% considered that the engineering roles specifically contributed to Building with Nature design, whereas $81 \%$ of participants recognised the relevance of the engineering roles to Building with Nature design in 2017. This difference is in part explained by the focus on stakeholder values in setting design requirements in 2017 as opposed to a constraint-focused problem definition in 2018. However, the experienced usefulness of the engineering roles seems also to reflect how seriously participants work with the roles and how much guidance they receive on applying the role prior to the workshop and within the design assignment. Overall both in 2017/2018, the roles were perceived to create added value for education (Question 13), the work environment (question 14), and students state they would recommend others to use the engineering roles in the design process (Table 2). Further, in terms of creativity, 56\% of the participants in 2018 felt the roles enhanced the divergent thinking process, while $15 \%$ neither agreed nor disagreed and $29 \%$ disagreed. However, the engineering roles were less useful in supporting convergent thinking, as only $33 \%$ felt it supported them with $30 \%$ neither agreeing nor disagreeing and a further $36 \%$ disagreeing. Overall, the roles were perceived to be useful in developing the most appropriate design solutions (67\% agreed/strongly agreed) and for developing an integrated design (59\% agreed to strongly agreed) and a more complete design $60 \%$ (agreed to strongly agreed). Finally, most of the participants considered the engineering roles relatively easy to use.

The integrated Building with Nature designs demonstrate an extremely wide distribution across the solution space for both the Hondsbossche and 
Pettemer Sea Defence case study and the Kinderdijk case study. A broad range of combinations of bio-geophysical and societal needs are evident in the design concepts, albeit designs for the tidal river area of Ablasserdam-Kinderdijk were less diverse.

The process of BwN design needs to adhere to the economically viable, environmentally friendly, quality of life bounds imposed by the doughnut model proposed in the introduction of this chapter. Moreover, the process also has to integrate across disciplinary sub-components and include the values of the stakeholders (CIGAS model, Kothuis et al., 2014) and take the different design-engineering roles into account. The engineering roles helped in explicating the values addressed in the problem definition and its translation into (diverse) design requirements. For example, the System Integrator can connect the problem of adequate emergency services (value) to the requirements of access to the beach, good road infrastructure and minimal pollution (design requirements). The Contextual Engineer can connect the problem of enhancing/preserving the natural environment and personal prosperity (values) to the requirements of recreational space and cultural heritage preservation activities (design requirements). Specialists can connect the problem of knowledge development on coastal infrastructure (value) to the requirements of structural stability, flood safety standards, and characteristic flora and fauna (design requirements). Deepening insight into design processes via the engineering roles, while trying to balance the biophysical and social aspects (a characteristic of Building with Nature projects), means that participants gained experience in interdisciplinary design. These integrative skills are becoming ever more important for future engineers to be able to deal with the complex and interdisciplinary design questions in the coming decades. From the workshops it turned out that teaching these skills to engineering students by means of engineering roles was helpful.

Summarising the evaluation of the participant's perceptions in the 2017 and 2018 Building with Nature workshops revealed that the use of engineering design roles supports the inherent interdisciplinary character of the Building with Nature design process. This is particularly relevant in the divergent and the evaluative phases of the design, where the integration and completeness of a design proposal is assessed. Knowledge of the diverse perspectives and values held by stakeholders and the implications for the local environment and the lived experience of the people affected by the proposed Building with Nature design makes for a more informed problem definition and widens the solution space. The participants valued that they were challenged to connect their engineering design competence to an authentic Building with Nature situation in each of the workshops. Most participants therefore considered the engineering roles particularly relevant for their future technical working environment, as well as for their education. 


\section{Concluding discussion}

Building with Nature infrastructure designs are characterised by disciplinary integration, non-linearity, diverse and fluid design requirements, and long-term time frames that balance the limitations of Earth's systems and the socio-technical systems created by humans. Three Building with Nature design workshops therefore provided the ideal context for investigating whether engineering roles enhance such interdisciplinary ways of working. In the first workshop in 2016, the explicit consideration of engineering roles within Building with Nature design processes was piloted. A modified version of the initial engineering roles prototype was then applied and evaluated in the second and third workshops in 2017 and 2018, leading to insights both on the engineering design roles and the interdisciplinary design context of Building with Nature.

Results indicate that the application of the engineering roles in each of the three workshops indeed supported interdisciplinary design. The engineering roles stimulate the consideration of stakeholder values and discussions about norms and values across disciplines as well as an appreciation of diverse stakeholder perspectives. Within the design team, engineering roles help the interdisciplinary discussion by shifting perspectives, finding and recognizing common ground, and the realisation of integrated solutions that fall within the solution space of the BwN doughnut.

A number of conditions for successful implementation within an authentic learning environment could be identified, namely:

- A clear and concise explanation of the engineering design roles,

- Some time to internalize the engineering role perspective before having to apply it,

- Effective integration of the engineering roles into a pre-structured design process,

- A design assignment that requires divergent thinking,

- No assignment of a single role to an individual person, but rather attaching the engineering role to the assignment in such a way that each team member can contribute to any and every engineering role perspective.

The engineering roles sustain an early, divergent way of looking at the design problem and support the search for common ground across the diverse perspectives of the team members, each bringing different disciplinary backgrounds to the design table. The engineering roles represent a new set of bridging values and the responsibility to engage in interdisciplinary processes, needed to successfully accomplish complex design processes as BwN. Both the engineering roles and the individual disciplinary perspectives contributed 
to the analysis of a complex real problem situation. However, reflecting on the design process from the engineering role perspective sustained integrative thinking in the early design process, and it sharpened the specification of design criteria and the evaluation at the end of the design process. These contributions are particularly relevant to Building with Nature design assignments, which require working across disciplines, coping with complex and fluid design requirements and accommodating non-linearity and dynamic environmental and social contexts. The inclusion of multiple perspectives in the definition of the design requirements, specifically those of local residents and authorities, served to broaden the solution space and the diversity of the final designs. Shifting the focus from "stakeholder requirements" to "a constraint-focused problem definition", led participants to value the use of engineering roles and helped them to be better equipped for interdisciplinary design challenges.

Further, it is likely that the engineering design roles would be more valuable for education at undergraduate and early postgraduate levels, rather than for $\mathrm{PhD}$ candidates who are familiar with the design cycle. The Building with Nature elements might be better identified when students already have strong training in this field or there is a marked identification with experts in the field and their engineering design roles. However, although experts are highly competent, they may be unaware of how they enact their engineering roles in their research or implementation practice. This can make it difficult for student participants to acquire deeper learning on engineering roles through interaction with the experts.

The engineering roles have been tested three times in small workshops. Each time the intervention was adapted to fit with the demands of the NSFPIRE program within which it was nested. This makes it difficult to draw broad conclusions that can be generalized. Nonetheless, we expect that the engineering design roles can support interdisciplinary learning processes in diverse environmental and engineering projects, and call upon researchers to add to the knowledge base on interdisciplinary design by evaluating applications of the engineering roles in diverse settings. We are particularly intrigued whether others will obtain similar results and are interested to learn whether the innovative character of Building with Nature solutions produced in the workshops are replicated. The interdisciplinary and contextual challenges of designing Building with Nature solutions provided a fertile testing ground. We urge others to apply the principles that we have provided above to create suitable educational settings and instructional processes as the next testing ground for interdisciplinary, environmental engineering design processes. 


\section{Acknowledgements}

Financial support from the NSF-PIRE program [grant no. 1545837] is acknowledged. The pilot study was partially financed by the CoCoChannel project [NWO-ALW grant no. 850.13.043]. Special thanks are extended to Danielle Ceulemans for her visualisation of the engineering roles and her contribution to the design and evaluation of the workshops. The participating senior researchers, $\mathrm{PhD}$, postgraduate, and undergraduate students and the experts and stakeholders who attended the workshops in 2016, 2017 and 2018 are warmly thanked. 


\section{References}

Beers, P.J. (2005). Negotiating Common Ground: Tools for Multidisciplinary Teams (Doctoral dissertation). Open University. https://www.ou.nl/documents/40554/111685/BeersPJproefschrift_2005.pdf/ 11132275-502c-448b-ad50-468b9659f1c7

Boix-Mansilla, V. (2010). Learning to Synthesize: The Development of Interdisciplinary Understanding. In C. Mitcham, J. B. Holbrook, J. T. Klein, \& R. Frodeman (Eds.), The Oxford Handbook of Interdisciplinarity (pp. 288-306). Oxford University Press.

Cunningham, S. W., Hermans, L. M., \& Slinger, J. H. (2014). A review and participatory extension of game structuring methods. EURO Journal on Decision Processes, 2(3-4), 173-193. https://doi.org/10.1007/ s40070-014-0035-8

d'Hont, F., \& Slinger, J. (2018). Application of a co-design process on a nature-based intervention in the coastal system of Texel, the Netherlands. 1-1. Poster session presented at 1st International Conference on Water Security, Toronto, Canada.

Fortuin, K.P.J. (2015). Heuristic principles to teach and learn boundary crossing skills in environmental science education (Doctoral dissertation). Wageningen University. https://edepot.wur.nl/356213

Hooimeijer, F., Kuzniecow Bacchin, T., Lafleur, F., van de Ven, F., Clemens, F., Broere, W., Laumann, S., Klaassen, R., \& Marinetti, C. (2016). Intelligent SUBsurface Quality: Intelligent use of subsurface infrastructure for surface quality. Delft University of Technology. http://resolver.tudelft.nl/uuid:6eff83a8-d0c6438e-aa42-0dbd03835ac9

Jay, T., Rose, J., \& Milligan, L. O. (2017). Adoption, adaptation, and integration: renegotiating the identity of educational research through interdisciplinarity. International Journal of Research \& Method in Education, 40(3), 223-230. https://doi.org/10.1080/1743727x.2017.1311478

Jescke, S. (2016, January 22). The role of Higher Education in The Fourth Industrial Revolution. World Economic Forum. https://www.weforum.org/agenda/2016/01/what-role-will-education-play-in-the-fourth-industrial-revolution/

Kamp, A. (2016). Engineering Education in the Rapidly Changing World: Rethinking the Vision for Higher engineering Education (2nd revised edition ed.). TU Delft, Faculty of Aerospace Engineering.

Kamp, A., \& Klaassen, R. G. (2016). Impact of global forces and empowering situations on engineering education in 2030. In Proceedings of the 12th international CDIO conference (pp. 1-20). CDIO.

Kothuis, B. L. M., Slinger, J. H., \& Cunningham, S. W. (2014). Contested issues game structuring approach-ClGAS workshop Houston report, results and reflection: Exploring stakeholder-based joint commitment to action for flood protection decision-making in the Houston Galveston Bay Area. Bee's Books.

Kothuis, B. L. M. (2017). Stakeholder value inclusive design: Using the contested issues game structuring approach (CIGAS) in Texas. In B. Kothuis, \& M. Kok (Eds.), Integral Design of Multifunctional Flood Defenses: Multidisciplinary Approaches and Examples (pp. 154-157). Delft University Publishers.

Kothuis, B. L. M., \& Slinger, J. H. (Eds.). (2018). Voices on Sustainable Ports in Africa: Stories from Tema Port, Ghana. Delft University Publishers. 
McKenney, S., \& Reeves, T. C. (2018). Conducting Educational Design Research (2nd ed.). Routledge. https:// doi.org/10.4324/9781315105642

Menken, S. B. J., Keestra, M., Rutting, L., \& Post, G. (2016). An Introduction to Interdisciplinary Research. Amsterdam University Press.

Newing, H. (2010). Interdisciplinary training in environmental conservation: definitions, progress and future directions. Environmental Conservation, 37(4), 410-418. https://doi.org/10.1017/ s0376892910000743

Raymond, C. M., Breil, M., Nita, M. R., Kabisch, N., de Bel, M., Enzi, V., ... \& Berry, P. (2017). An impact evaluation framework to support planning and evaluation of nature-based solutions projects. Report prepared by the EKLIPSE Expert Working Group on Nature-Based Solutions to Promote Climate Resilience in Urban Areas. Centre for Ecology and Hydrology.

Repko, A., Navakas, F., \& Fiscella, J. (2007). Integrating interdisciplinarity: How the theories of common ground and cognitive interdisciplinarity are informing the debate on interdisciplinary integration. Issues in Interdisciplinary Studies.

Schwab, K. (2017). The Fourth Industrial Revolution. Reed Business Education.

Slinger, J. (2015, October 8). Building with Nature @ TU Delft 2015 [Dataset]. https://data.4tu.nl/collections/ Building_with_Nature_TU_Delft_2015/5065574

Slinger, J. H. (2016, March 29). Engineering: Building with Nature 101x: series of 11 videos [Dataset]. https:// data.4tu.nl/collections/Engineering_Building_with_Nature_101x_series_of_11_videos/5065442

Slinger, J. H., Cunningham, S. W., Hermans, L. M., Linnane, S. M., \& Palmer, C. G. (2014). A game-structuring approach applied to estuary management in South Africa. EURO Journal on Decision Processes, 2(3-4), 341-363. https://doi.org/10.1007/s40070-014-0036-7

Stentoft, D. (2017). From saying to doing interdisciplinary learning: Is problem-based learning the answer?. Active Learning in Higher Education, 18(1), 51-61. https://doi.org/10.1177/1469787417693510

van den Bossche, P., Gijselaers, W. H., Segers, M., \& Kirschner, P. A. (2006). Social and Cognitive Factors Driving Teamwork in Collaborative Learning Environments: Team Learning Beliefs and Behaviors. Small Group Research, 37(5), 490-521. https://doi.org/10.1177/1046496406292938

Voorendt, M. (2017). Design principles of multifunctional flood defences (Doctoral dissertation). Delft University of Technology. https://doi.org/10.4233/uuid:31ec6c27-2f53-4322-ac2f-2852d58dfa05

Waterman, R. E. (2010). Integrated coastal policy via Building with Nature (Doctoral dissertation). Delft University of Technology. http://resolver.tudelft.nl/uuid:fa9a36f9-7cf8-4893-b0fd-5e5f15492640

de Vriend, H. J., van Koningsveld, M., Aarninkhof, S. G. J., de Vries, M. B., \& Baptist, M. J. (2015). Sustainable hydraulic engineering through building with nature. Journal of Hydro-Environment Research, 9(2), 159171. https://doi.org/10.1016/j.jher.2014.06.004

de Vriend, H. J., \& van Koningsveld, M. (2012). Building with nature - Thinking, acting and interacting differently. Ecoshape. 